WellBeing International

WBI Studies Repository

8-1999

\title{
Asymmetry and Fighting Performance in the Shore Crab Carcinus maenas
}

Lynne U. Sneddon

University of Glasgow

John P. Swaddle

University of Chicago

Follow this and additional works at: https://www.wellbeingintlstudiesrepository.org/acwp_vsm

Part of the Animal Studies Commons, Behavior and Ethology Commons, and the Comparative Psychology Commons

\section{Recommended Citation}

Sneddon, L. U., \& Swaddle, J. P. (1999). Asymmetry and fighting performance in the shore crab Carcinus maenas. Animal behaviour, 58(2), 431-435.

This material is brought to you for free and open access by WellBeing International. It has been accepted for inclusion by an authorized administrator of the WBI Studies Repository. For more information, please contact wbisr-info@wellbeingintl.org.

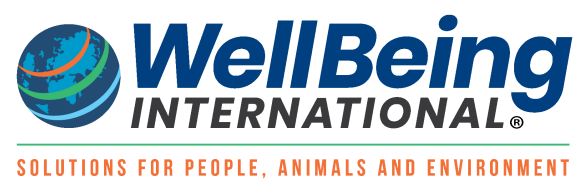




\title{
Asymmetry and Fighting Performance in the Shore Crab Carcinus maenas
}

\author{
Lynne U. Sneddon ${ }^{1}$ \& John P. Swaddle ${ }^{2}$ \\ ${ }^{1}$ University of Glasgow \\ ${ }^{2}$ University of Chicago
}

\begin{abstract}
Fluctuating asymmetries (left-right differences in symmetric traits) can be negatively related to fitness parameters in a number of biological systems. Hence, it has been suggested that symmetric individuals should outcompete asymmetric individuals during intraspecific agonistic encounters. However, there is a lack of experimental evidence for such a relationship. We investigated the relationship between trait asymmetry (both directional and fluctuating asymmetry) and the outcome of agonistic encounters among size-matched male shore crabs. Our findings indicate that cheliped ('weapon claw') directional asymmetry is not related to the outcome of fights, whereas fluctuating asymmetry in the fifth pereiopod, but not the second pereiopod, is negatively related to the likelihood of winning conspecific aggressive encounters. This relationship is most readily explained by a biomechanical advantage in symmetric individuals, as the fifth pereiopod is likely to be mechanically important in maintaining stability and balance during fighting. There is no evidence that asymmetry (in traits that display fluctuating asymmetry) is related to an intrinsic individual quality factor. None the less, the relative mechanical advantage of low asymmetry may give rise to fitness benefits in symmetric crabs that may have evolutionary consequences.
\end{abstract}

Fluctuating asymmetry is an estimate of developmental instability and represents the minor, random deviation from symmetry that occurs during the development of otherwise symmetric traits (Ludwig 1932). There has been much recent interest in the evolutionary relevance of these small asymmetries, as there is accumulating evidence that relatively symmetric individuals experience fitness advantages in some taxa (reviews in Møller \& Pomiankowski 1993; Watson \& Thornhill 1994; Møller \& Swaddle 1997). There is also some evidence to indicate direct selection for symmetric individuals, both in terms of natural (e.g. Swaddle 1997) and sexual selection processes (e.g. Møller 1993; Swaddle \& Cuthill 1994).

It has been suggested that symmetric individuals may gain fitness advantages by outcompeting relatively asymmetric individuals during intraspecific agonistic encounters (Thornhill 1992; Thornhill \& Sauer 1992; Liggett et al. 1993; Malyon \& Healy 1994; Møller et al. 1996). However, there are a number of conflicting correlations between social dominance and trait asymmetry (Swaddle \&Witter 1994; Witter \& Swaddle 1994; Hoysak \& Ankney 1996; Dufour \& Weatherhead 1998) and, additionally, none of the experimental investigations of the influence of trait asymmetry on agonistic encounters follows the predicted pattern (Møller 1992a, 1993; Swaddle \& Witter 1995; Swaddle 1996; Jablonski \&Matyjasiak 1997). Therefore, the influence of fluctuating asymmetry on the outcome of intraspecific agonistic encounters is not clear; there is evidence from a range of taxa that on some occasions symmetric individuals do better, whereas on other occasions symmetry does not predict competitive ability. Hence, there is a need for further experimental investigations of the relationship between developmental stability and dominance. Here, we investigated the relationship between asymmetry and fight outcome in the male shore crab. 
Agonistic interactions between crustaceans occur in the context of competition for resources such as food, mates or shelter, as well as resulting from chance encounters (Hazlett 1968, 1974; Jachowski 1974; Rubenstein \& Hazlett 1974; Hyatt 1983; Reid et al. 1994; Sneddon et al. 1997a). The majority of studies have indicated that larger-bodied crabs are more successful in contests against smaller conspecifics (Callinectes sapidus: Jachowski 1974; portunid spp.: Huntingford et al. 1995); but when size disparity is small, body size is not a reliable indicator of the outcome. In shore crabs, there is experimental evidence to indicate that claw size is a more reliable indicator of fight outcome than body size (Sneddon et al. 1997b). However, when claw sizes were similar between the two contestants, neither claw size nor body size were accurate predictors of fight outcomes (Sneddon et al. 1997b). In this study, we staged agonistic encounters between male crabs that were paired for both claw (mean claw size) and body size. This experimental design allowed us to investigate the relations between trait asymmetry and the outcome of fights, whilst minimizing the influence of trait size.

\section{METHODS}

We obtained 16 pairs of size-matched male Carcinus maenas (carapace width range $55-80 \mathrm{~mm}$ ) from the University Marine Biological Station, Millport, Isle of Cumbrae, Scotland, where they had been freshly caught by creeling from the Clyde Sea area. On their arrival we transferred the crabs to individual holding tanks $(18 \times 21 \times 23 \mathrm{~cm})$, supplied with circulating sea water (salinity $32-34 \%$ ) maintained at $12 \pm 2$ ) C and on a 12:12 $\mathrm{h}$ light:dark cycle, with experiments being carried out in the light period. We kept the crabs in these isolated conditions for at least 7 days prior to any behavioural observations.

We staged 16 fights by placing two size-matched crabs (matched to within $1 \mathrm{~mm}$ for both carapace width and mean claw length) in a glass observation tank $(48 \times 43 \times 34 \mathrm{~cm})$, with a gravel substratum, filled with aerated sea water (environmental conditions as above) which was screened from visual disturbance. Crabs were separated by a vertically sliding opaque partition to allow them a settling time of 15 min in continued isolation. To reduce the possibility of chemical communication, the air and water pumps were switched off to minimize mixing during the settling period. The tank was illuminated from above at a light intensity of $1.82-2.66 \mu \mathrm{E} / \mathrm{m}^{2}$ per s at the top and $0.89-1.40 \mu \mathrm{E} / \mathrm{m}^{2}$ per $\mathrm{s}$ at the bottom of the tank. We made observations through a small opening in the screen. After the initial settling period and when both crabs were stationary, the partition was raised from outside the screen by a pulley. We recorded the actions of both crabs using a laptop computer as an event recorder. These behavioural data are presented elsewhere (Sneddon et al. 1997a). The end of a contest was judged to be when the two crabs separated and did not interact for $5 \mathrm{~min}$. The winner was the crab that successfully climbed on top of its opponent or elicited repeated retreats from the other crab (the loser). Male crabs display similar behavior in the wild as that observed in our experimental arena and the behavioural content of fighting bouts is identical between laboratory and natural conditions (Sneddon et al., in press).

After the fights were conducted, we killed all crabs by placing them in liquid nitrogen. We measured length of the dactylus (most distal segment) of the cheliped (i.e. the 'weapon' claw) on both left and right sides with dial callipers (to 0.1-mm accuracy) three times in nonsequential order. Similarly, we measured the propodus (second most distal segment) of the second pereiopod (leg 2, numbered in ascending order from anterior to posterior) and the propodus of the fifth pereiopod (i.e. most posterior leg) by the same method, on both left and right sides. There was directional asymmetry in cheliped length in which the right claw was significantly larger than the left $(t=6.28, N=32, P<0.001)$ but still exhibited a normal distribution of signed asymmetry (left minus right) scores (Anderson-Darling normality test: $a^{2}=0.478, N=32$, $P=0.221$ ). The signed asymmetry scores of both pereiopods 2 and 5 showed the statistical properties of fluctuating asymmetry, that is, a normal distribution (leg 2: $a^{2}=0.461, N=32, P=0.451$; leg $5: a^{2}=0.258$, $\mathrm{N}=32, P=0.637$ ) around a mean of zero (leg 2: $t=1.79, N=32, P=0.083$; leg $5: t=1.16, N=32, P=0.25$ ) (Palmer 1994). Additionally, signed and unsigned asymmetry measures were far greater than 
measurement error $\left(F_{31,124}>22.12, P<0.00001\right.$, in all cases; Swaddle et al. 1994). We measured leg segments undamaged because in estimates of fluctuating asymmetry it is important to exclude asymmetries resulting from damage. We calculated absolute $(L-R)$ asymmetry values for each trait on each individual by taking the average of the three repeated measures.

We examined the asymmetry differences between winners and losers of fights using Wilcoxon signedranks tests (Siegel \& Castellan 1988), in which the data were blocked by 'fight'. We used paired $t$ tests to analyse differences in trait size between winners and losers and Spearman rank correlation analyses to determine the relationships between leg asymmetries and trait size. We explored differences in the magnitude of asymmetry among traits using Friedman nonparametric two-way analysis of variance and Wilcoxon signed-ranks tests. Two-tailed tests of significance are used throughout.

\section{RESULTS AND DISCUSSION}

\section{Directional and Fluctuating Asymmetry}

Asymmetry in the cheliped, which showed a right-biased directionality, was positively related to overall cheliped size (i.e. $(L+R) / 2)$; but there was no relationship between asymmetry and trait size in either of the pereiopods (cheliped: $r S=0.397, N=32, P=0.020$; pereiopod 2: $r_{S}=0.030, N=32, P=0.866$; pereiopod 5: $r_{\mathrm{S}}=0.128, N=32, P=0.471$ ). The asymmetry observed in cheliped length (i.e. showing the population characteristic of directional asymmetry) was much greater than the asymmetry observed in the length of the second and fifth pereiopod (showing the population characteristics of fluctuating asymmetry) (Friedman: $S_{2}=47.15, P<0.001$; cheliped versus average asymmetry of pereiopods 2 and 5 , Wilcoxon: $T=527.0, N=32, P<0.001$ ); however, there was no difference in magnitude of asymmetry between the second and fifth pereiopods ( $T=287, N=32, P=0.136)$. The mean $( \pm S E)$ asymmetries measured here were $10.22 \pm 0.94 \%$ for the directional asymmetry observed in the chelipeds, and $1.76 \pm 0.28$ and $1.14 \pm 0.15 \%$ for second and fifth pereiopod, respectively. This difference in asymmetry asymmetryand fluctuating asymmetry has been reported on many previous occasions and probably reflects the differences in function and developmental origins of these two fundamentally different forms of morphological asymmetry (Van Valen 1962; Møller \& Pomiankowski 1993).

\section{Fight Outcome and Trait Size}

There were no size differences between winners and losers for any of the three traits measured $(t<1.77$, $N=16$, NS, in all cases). This supported previous findings, which indicated that cheliped and body size are poor predictors of fight outcome when combatants are of similar overall size (Sneddon et al. 1997b).

\section{Fight Outcome and Trait Asymmetry}

Signed directional asymmetry in cheliped length was not related to whether crabs won individual fights (Wilcoxon: $T=79.0, N=16, P=0.587$ ), nor was unsigned deviation of this asymmetry from the mean directional asymmetry for the whole population related to fight outcome ( $T=74.0, N=16, P=0.383)$. The lack of association between cheliped features and fight outcome may, in part, be related to our sizematching procedure. The matching of combatants by both cheliped length and body size resulted in little variation in cheliped directional asymmetry between pairs, hence reducing the likelihood of detecting a fighting difference associated with this variable. In the wild, cheliped directional asymmetry may influence the outcome of some fights if individuals are not size-matched and if they display much greater variation in this character.

Individual asymmetry in the second pereiopod was not related to fight outcome ( $T=49.5, N=16, P=0.352)$. However, asymmetry in the fifth pereiopod did differ between winners and losers $(T=10.5, N=16$, 
$P=0.003$ ); crabs that won fights were more symmetric than losers (Fig. 1). These data suggest that the fifth pereiopod asymmetry (which displays fluctuating asymmetry) can influence, or is associated with factors that influence, the outcome of fights in male shore crabs, independent of any association between fighting ability and body size. An increased competitive ability in relatively symmetric individuals is likely to have a positive influence on individual survival, as shore crabs often compete in this manner over important resources such as food, mates and shelter (e.g. Rubenstein \& Hazlett 1974; Hyatt 1983; Reid et al. 1994; Sneddon et al. 1997a). Therefore, our data suggest that symmetric individuals could experience an increased likelihood of survival due to their enhanced competitive ability.

Figure 1. Mean \pm SE asymmetry $(\mathrm{mm})$ (in a population that shows fluctuating asymmetry) of the (a) second and (b) fifth pereiopods for crabs that won $\square$ or lost $\square$ paired staged fights.
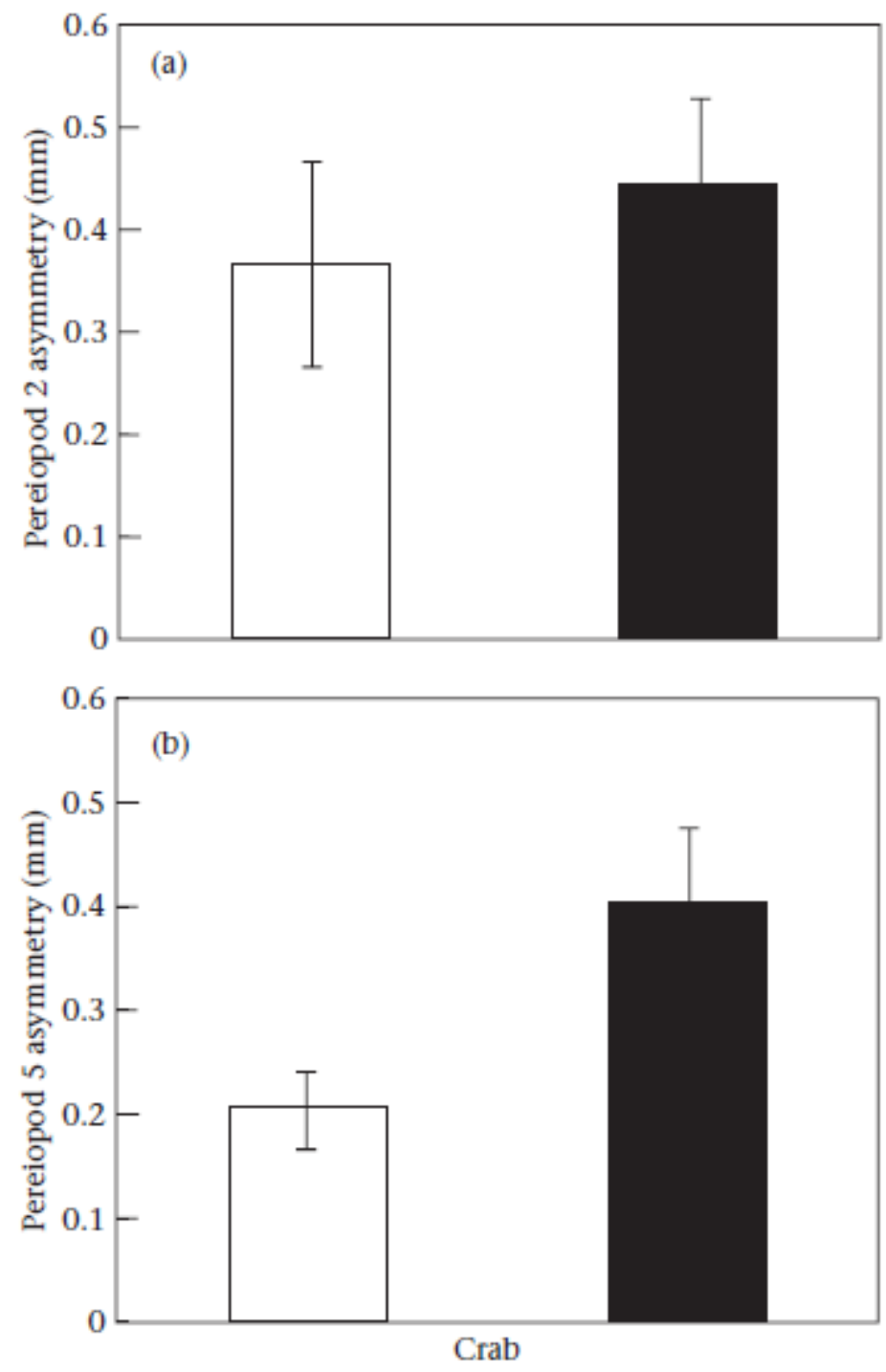

Negative relationships between the size and asymmetry of combative weapons have been cited as examples of symmetric individuals performing well during intraspecific encounters (e.g. Møller 1992b). Additionally, previous studies have shown that symmetric individuals exhibit increased social dominance 
in a number of contexts (Thornhill 1992; Thornhill \& Sauer 1992; Liggett et al. 1993; Malyon \& Healy 1994; Møller et al. 1996); but there are also studies indicating that symmetric individuals do not outcompete their asymmetric competitors during agonistic encounters (Swaddle \& Witter 1994; Witter \& Swaddle 1994; Hoysak \& Ankney 1996; Dufour \& Weatherhead 1998). We are aware of only five experimental investigations of trait asymmetry and intraspecific interactions where the asymmetry of traits have been manipulated independent of extraneous confounding factors. In all five cases there were no associations between the outcome of agonistic encounters and asymmetry of the manipulated traits (Møller 1992a, 1993; Swaddle \& Witter 1995; Swaddle 1996; Jablonski \& Matyjasiak 1997). Therefore, the general relationship between asymmetry and fighting performance is not clear. The data we present here, however, provide support for the hypothesis that symmetric individuals outcompete their asymmetric counterparts, when body size is taken into account.

The purported relationships between fluctuating asymmetry and fighting ability recorded in other taxa have been discussed in terms of direct and indirect mechanisms. A direct mechanism would imply that asymmetry is either directly assessed during agonistic encounters and this influences fight outcome (i.e. asymmetry is a 'signal'; cf. Møller 1992a; Swaddle, in press), or that phenotypic asymmetry directly influences fighting performance. An indirect mechanism could operate if the asymmetry is related to some unidentified property of an individual, which in turn, enhanced fighting performance (i.e. asymmetry is a general viability or fitness indicator).

Our data tend to support the notion that asymmetry directly influences fighting ability. Contests between male shore crabs usually consist of a 'wrestle' or pushing contest, where both crabs face one another standing high on their posterior walking legs (pereiopods 4 and 5), wrap the first pair of walking legs around each other and push against one another in what appears to be a trial of strength (for details see Sneddon et al. 1997a). This can result in one of the crabs being pushed backwards by the other and quite often one crab loses balance and finishes lying upside down on the substrate with the victorious opponent on top of it. This pushing contest is decisive in the outcome of the fight as the first crab to retreat from the wrestle or be overturned is the eventual loser (Sneddon et al. 1997a). We propose that asymmetry in the hindmost legs (i.e. the fifth pereiopod) could create a turning moment that would result in a loss of stability and balance (cf. Thomas 1993). Behavioural observations of the crabs indicates that in five out of the 16 staged fights ( $31 \%$ of all fights), asymmetric individuals lost the encounter by being turned over by their relatively symmetric opponent. Our favouring of the direct mechanism hypothesis is further supported by the lack of a relationship between asymmetry in the second pereiopod and fight outcome. An asymmetry in the second pereiopod would have relatively little mechanical influence on fighting ability, and if an indirect relationship between performance and asymmetry operated, we would expect to see a negative relationship between asymmetry in the second pereiopod and the likelihood of winning a fight.

Evidence for an asymmetry-signalling hypothesis is equivocal. Visual assessment of asymmetry seems unlikely as the measured asymmetries were small (1-2\% of trait size) and these crabs do not appear to use visual cues during prefight engagement behaviour (Sneddon et al. 1997a). The crabs appear to rely more on tactile cues to assess each other during an early wrestling period of each fighting bout. A tactile signalling system is more plausible, as instability caused by asymmetry in the fifth pereiopod could feasibly be detected by an opponent during prefight engagement. Whether a signalling system operates is unclear, and our findings can most parsimoniously be explained by phenotypic asymmetry directly influencing mechanical performance.

In summary, it would appear that asymmetry in the hindmost legs of male shore crabs is related to conspecific fighting performance: symmetric individuals are more likely to win fights. This relationship can most readily be explained by a direct mechanical advantage of symmetry rather than asymmetry (fluctuating asymmetry) being related to some intrinsic property of an individual. To our knowledge, this is 
the first study to demonstrate empirically that symmetric individuals can gain a competitive advantage through a simple relationship between biomechanical functioning and developmental instability. Even though it is not necessary to invoke an hypothesis that relates asymmetry (in traits that display fluctuating asymmetry) to an intrinsic, unidentified 'quality' factor, our findings suggest that symmetric individuals should encounter fitness benefits that may lead to selection pressures favouring relatively symmetric individuals.

\section{Acknowledgments}

We thank Alan Taylor, Felicity Huntingford, Innes Cuthill, Bryant Furlow, Tara Armijo-Prewitt, Judy Stamps and two anonymous referees for helpful comments on earlier versions of this manuscript. L.U.S. was supported by a NERC studentship GT4/95/110; J.P.S. was funded by a NERC postdoctoral research fellowship, the Royal Commission for the Exhibition of 1851 and the Royal Society of London.

\section{References}

Dufour, K. W. \& Weatherhead, P. J. 1998. Bilateral symmetry and social dominance in captive male redwinged blackbirds. Behavioral Ecology and Sociobiology, 42, 71-76.

Hazlett, B. A. 1968. Size relationships and aggressive behaviour in the hermit crab Clibanarius vittatus. Zeitschrift für Tierpsychologie, 27, 369-374.

Hazlett, B. A. 1974. Field observations on the interspecific agonistic behaviour in hermit crabs. Crustaceana, 26, 133-138.

Hoysak, D. J. \& Ankney, C. D. 1996. Correlates of behavioural dominance in mallards and American black ducks. Animal Behaviour, 48, 248-250.

Huntingford, F. A., Taylor, A. C., Smith, I. P. \& Thorpe, K. E. 1995. Behavioural and physiological studies of swimming crabs. Journal of Experimental Marine Biology and Ecology, 193, 21-39.

Hyatt, G. W. 1983. Qualitative and quantitative dimensions of crustacean aggression. In: Studies in Adaptation: the Behaviour of the Higher Crustacea (Ed. by S. Rebach \& D. W. Dunham), pp. 113-139. New York: J. Wiley.

Jablonski, P. G. \& Matyjasiak, P. 1997. Chaffinch (Fringilla coelebs) epaulette display depends on the degree of exposure but not symmetry of intruder's epaulettes. Behaviour, 134, 1115-1121.

Jachowski, R. L. 1974. Agonistic behaviour of the blue crab, Callinectes sapidus. Behavior, 50, 232-253.

Liggett, A. C., Harvey, I. F. \& Manning, J. T. 1993. Fluctuating asymmetry in Scatophaga stercoraria L.: successful males are more symmetrical. Animal Behaviour, 45, 1041-1043.

Ludwig, W. 1932. Das Rechts-Links Problem im Tierrich und beim Menschen. Berlin: Springer-Verlag.

Malyon, C. \& Healy, S. 1994. Fluctuating asymmetry in antlers of fallow deer, Dama dama, indicates dominance. Animal Behaviour, 48, 248-250.

Møller, A. P. 1992a. Female swallow preference for symmetrical male sexual ornaments. Nature, 357, 238-240. 
Møller, A. P. 1992b. Patterns of fluctuating asymmetry in weapons: evidence for reliable signalling of quality in beetle horns and bird spurs. Proceedings of the Royal Society of London, Series B, 248, 199-206.

Møller, A. P. 1993. Female preference for apparently symmetrical male sexual ornaments in the barn swallow Hirundo rustica. Behavioral Ecology and Sociobiology, 32, 371-376.

Møller, A. P. \& Pomiankowski, A. 1993. Fluctuating asymmetry and sexual selection. Genetica, 89, 267279.

Møller, A. P. \& Swaddle, J. P. 1997. Asymmetry, Developmental Stability and Evolution. Oxford: Oxford University Press.

Møller, A. P., Cuervo, J. J., Soler, J. J. \& Zamora-Muñz, C. 1996. Horn asymmetry and fitness in gemsbok Oryx g. gazella. Behavioral Ecology, 7, 247-253.

Palmer, A. R. 1994. Fluctuating asymmetry analyses: a primer. In: Developmental Instability: its Origins and Evolutionary Implications (Ed. by T. A. Markow), pp. 335-364. Dordrecht: Kluwer.

Reid, D. G., Abello, P., Warman, C. G. \& Naylor, E. 1994. Size related mating success in the shore crab, Carcinus maenas. Journal of Zoology, 232, 399-407.

Rubenstein, D. I. \& Hazlett, B. A. 1974. Examination of the agonistic behaviour of the crayfish, Orconectes virilis by character analysis. Behavior, 50, 193-216.

Siegel, S. \& Castellan, N. J. 1988. Nonparametric Statistics for the Behavioral Sciences. 2nd edn. Singapore: McGraw-Hill. Sneddon, L. U., Huntingford, F. A. \& Taylor, A. C. 1997a. The influence of resource value on the agonistic behaviour of the shore crab, Carcinus maenas (L.). Marine and Freshwater Behaviour and Physiology, 30, 225-237.

Sneddon, L. U., Huntingford, F. A. \& Taylor, A. C. 1997b. Weapon size vs. body size as predictor of winning fights between shore crabs, Carcinus maenas (L.). Behavioral Ecology and Sociobiology, 41, 237-242.

Sneddon, L. U., Taylor, A. C. \& Huntingford, F. A. In press. Combined field and laboratory studies on the influence of an ecological factor on the physiological consequences of fighting in shore crabs, Carcinus maenas (L.). Proceedings of the IV International Crustacean Congress.

Swaddle, J. P. 1996. Reproductive success and symmetry in zebra finches. Animal Behaviour, 51, 203210.

Swaddle, J. P. 1997. Developmental stability and predation success in an insect predator-prey system. Behavioral Ecology, 8, 433-436.

Swaddle, J. P. In press. Visual signalling by asymmetry: a review of perceptual processes. Philosophical Transactions of the Royal Society of London, Series $B$.

Swaddle, J. P. \& Cuthill, I. C. 1994. Female zebra finches prefer males with symmetrically manipulated chest plumage. Proceedings of the Royal Society of London, Series B, 258, 267-271.

Swaddle, J. P. \& Witter, M. S. 1994. Food, feathers and fluctuating asymmetry. Proceedings of the Royal Society of London, Series B, 255, 147-152. 
Swaddle, J. P. \& Witter, M. S. 1995. Chest plumage, dominance and fluctuating asymmetry in female starlings. Proceedings of the Royal Society of London, Series B, 260, 219-223.

Swaddle, J. P., Witter, M. S. \& Cuthill, I. C. 1994. The analysis of fluctuating asymmetry. Animal Behaviour, 48, 986-989.

Thomas, A. L. R. 1993. The aerodynamic costs of asymmetry in the wings and tails of birds: asymmetric individuals can't fly around tight corners. Proceedings of the Royal Society of London, Series B, 254, 181-189.

Thornhill, R. 1992. Fluctuating asymmetry, interspecific aggression and male mating tactics in two species of Japanese scorpionflies. Behavioral Ecology and Sociobiology, 30, 357-363.

Thornhill, R. \& Sauer, P. 1992. Genetic sire effects on the fighting ability of sons and daughters and mating success of sons in a scorpionfly. Animal Behaviour, 43, 255-264.

Van Valen, L. 1962. A study of fluctuating asymmetry. Evolution, 16, 125-142.

Watson, P. J. \& Thornhill, R. 1994. Fluctuating asymmetry and sexual selection. Trends in Ecology and Evolution, 9, 21-25.

Witter, M. S. \& Swaddle, J. P. 1994. Fluctuating asymmetries, competition and dominance. Proceedings of the Royal Society of London, Series B, 256, 299-303. 